\title{
Inactivation of Microbial Food Contamination of Plastic Cups Using Nonthermal Plasma and Hydrogen Peroxide
}

\author{
Tereza Kordová $\left(\mathbb{D},{ }^{1}\right.$ Vladimír Scholtz $\left(\mathbb{D},{ }^{1}\right.$ Josef Khun, ${ }^{1}$ Hana Soušková, ${ }^{2}$ Pavel Hozák, ${ }^{1,3}$ \\ and Miroslav Čeřovský ${ }^{4}$ \\ ${ }^{1}$ Department of Physics and Measurements, Faculty of Chemical Engineering, University of Chemistry and Technology, \\ Prague, Czech Republic \\ ${ }^{2}$ Department of Computing and Control Engineering, Faculty of Chemical Engineering, University of Chemistry and Technology, \\ Prague, Czech Republic \\ ${ }^{3}$ Institute of Physics, Czech Academy of Sciences, Prague, Czech Republic \\ ${ }^{4}$ Department of Food Preservation, Faculty of Food and Biochemical Technology, University of Chemistry and Technology, \\ Prague, Czech Republic
}

Correspondence should be addressed to Vladimír Scholtz; scholtz@aldebaran.cz

Received 27 March 2018; Revised 4 June 2018; Accepted 24 June 2018; Published 16 July 2018

Academic Editor: Anet Režek Jambrak

Copyright (c) 2018 Tereza Kordová et al. This is an open access article distributed under the Creative Commons Attribution License, which permits unrestricted use, distribution, and reproduction in any medium, provided the original work is properly cited.

\begin{abstract}
The inactivation effect of the combination of nonthermal plasma and hydrogen peroxide aerosol for the microbial decontamination of inner surface of cylindrical container buckets is studied on one bacterial and seven filamentous micromycete species and on airborne-contaminated cups. While the decontamination by single nonthermal plasma or hydrogen peroxide is not observable after $120 \mathrm{~s}$, the strong decontamination by their combination occurs after $30 \mathrm{~s}$ of exposure. Moreover, observed total elimination of airborne contamination of plastic cups predetermines this method as a suitable alternative to the currently used method based on the application of hydrogen peroxide.
\end{abstract}

\section{Introduction}

The microbial contaminants present a serious problem, among others, in food processing, and their elimination is often desired in many areas. There are many papers studying the microbial decontamination of food and food packaging materials by conventional as well as alternative physical or chemical methods, for example, reviews [1,2] or research articles as $[3,4]$ comprise the ultrahigh pressure processing (cold pasteurization), ionizing radiation, electron beam, UV radiation, pulsed electric field, magnetic field, ozone, or other chemical agents as peracetic acid, acetic acid, hydrogen peroxide, linalool, carvacrol, or thymol. Ultrasound is used in [5], pulsed light systems are used in [6] or [7], the effect of radio frequency heating is used in [8], and recently also the shaped electrical pulses have been studied [9].
One possible alternative presents the microbial decontamination by nonthermal plasma (NTP). There are already a lot of works describing its biological effects, devoted mainly to the killing of bacteria or various applications in medicine. See, for example, reviews $[10,11]$ or other studies [12-18]. The contamination may often arise also from the packaging materials $[19,20]$; therefore, many papers describe basic studies of NTP application in food packaging. Several papers deal with decontamination of food packaging materials by NTP generated under low pressure as [21-25]. Following works use NTP in more economically and easier-to-use form at atmospheric pressure, for example, the decontamination of polymer foils [26], plastic tray, aluminum foil and paper cup [27], PET film [28], dried laver [29], shell eggs [30], or sealed packages [31]. Also other effects of NTP treatment on food packaging materials as 


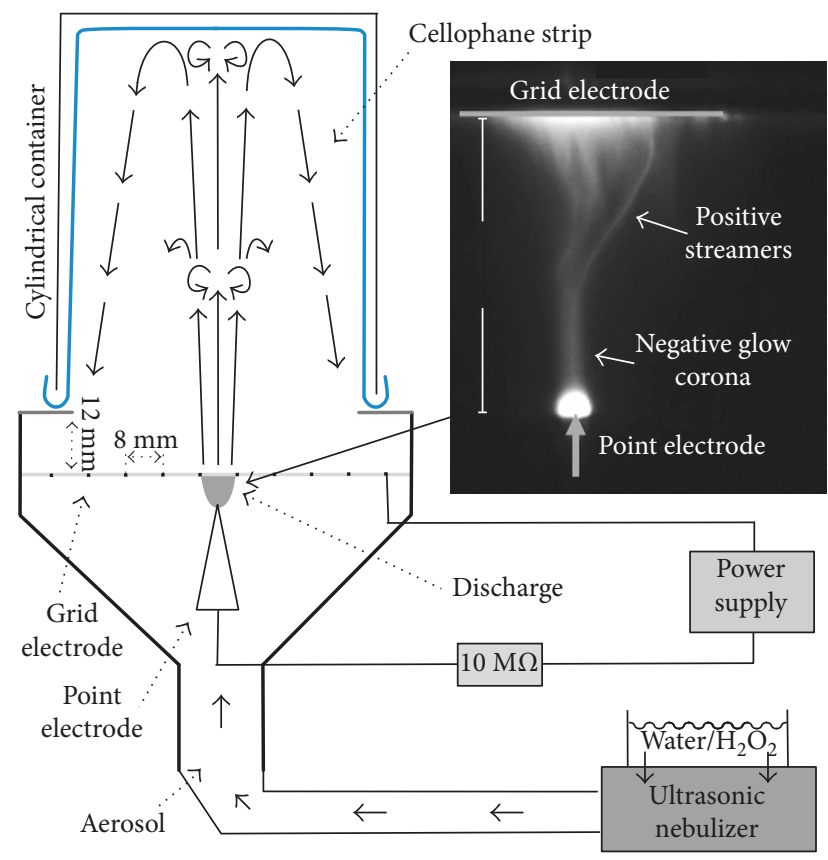

FIGURE 1: Schematic view of the apparatus and picture of plasma active area. Nebulized hydrogen peroxide mixed with air flows to the discharge active plasma region where active particles are produced and carried by the ion wind to the sample.

influence on contact angle, wettability, roughness, and surface energy are studied and summarized in [32, 33].

To increase the decontamination efficiency, the atmosphere where the plasma is generated may be also enriched by some other microbicidal substances, for example, hydrogen peroxide or peracetic acid. Such commercial sterilizers already exist; however, they work at reduced pressure and massive apparatus, resembling autoclave, is needed; for details, see, for example, the review [11] or [34].

In this paper, we combine the benefits of NTP generated at atmospheric pressure, where no additional vacuum apparatus is necessary, and the addition of other bactericidal agent-hydrogen peroxide. This paper follows our previous articles $[35,36]$, where synergy decontaminating effect of the combination of NTP with hydrogen peroxide aerosol was demonstrated on agar surfaces and dry cellophane foils. Here, we present the study of volume decontamination effect of plastic objects on both defined and airborne contamination. As first, we confirm the previously observed synergy effect in volume also. Following, we have studied the decontamination of large volumes with high concentration of microorganisms so that we could subsequently demonstrate the reliable inactivation of much lower airborne contamination of packaging vessels.

\section{Materials and Methods}

2.1. Plasma Generation. The NTP was generated in the apparatus previously described in $[35,36]$. The point-to-wire discharge burns between the point and grid electrode in an open chamber where the hydrogen peroxide or pure water aerosol was added to the air atmosphere. The point electrode was represented by the tip of a syringe needle Medoject $(0.6 \times 30 \mathrm{~mm})$ situated vertically to the grid electrode. The grid consisted of stainless steel wire of $0.25 \mathrm{~mm}$ diameter forming the net with a mesh size of $8 \mathrm{~mm}$. The electrode distance was adjusted to $6 \mathrm{~mm}$. The discharge was stabilized by the connection of a serial resistance of $10 \mathrm{M} \Omega$ into the circuit. The polarity of the point electrode was set as negative and the grid electrode as positive. The discharge voltage was set to $2.7 \mathrm{kV}$ which corresponds to the current of $500 \mu \mathrm{A}$. For more details about this discharge denominated as pulseless glow, see our previous paper [37], where several stabilized discharges are studied. For other information about the corona discharge stabilization and its characteristic, see, for example, papers $[38,39]$. The aerosol of pure water or $10 \%$ hydrogen peroxide was generated by the ultrasonic nebulizer (Lucky Reptile, Super Fog SF-1) and mixed with the air; the volume of nebulized water or hydrogen peroxide in the air mixture was $0.40 \pm 0.03 \mathrm{ml} / \mathrm{l}$ (determined by the weight loss). This mixture flowed to the discharge area and created the discharge atmosphere. The aerosol flow was adjusted to the value of $2.0 \pm 0.1 \mathrm{l} / \mathrm{min}$ (determined by ebulliometry). The distance between the decontaminated object and the grid electrode was set to $12 \mathrm{~mm}$. The schematic experimental arrangement and the picture of plasma active area are shown in Figure 1.

2.2. Microorganisms under Study. The microorganisms under study were bacteria Staphylococcus epidermidis (wild strain) and filamentous micromycetes Aspergillus oryzae (DBM 4002), Aspergillus niger (DBM 4054), Cladosporium sphaerospermum (DBM 4282), Alternaria sp. (DBM 4004), Eurotium sp. (wild strain 1), Eurotium sp. (wild strain 2), and Trichoderma atroviride (wild strain). DBM is the Collection of Yeasts and Industrial Microorganisms of the Department of Biochemistry and Microbiology at the University of Chemistry and Technology, Prague. Wild strains were contaminants isolated from food products. In all cases, the bacteria were cultivated on the Mueller-Hinton agar (Oxoid) at $37^{\circ} \mathrm{C}$ overnight for 18 hours and the micromycetes were cultivated on the Sabouraud medium (Oxoid) agar at $25^{\circ} \mathrm{C}$ for 5 days to become sporulated.

The suspension of each microorganism under study was prepared by the mixing of loopful taken from the surface of grown culture into the sterile water; in the case of micromycetes, Tween 80 in ratio $0.1 \%$ was added into the suspension to improve wettability. It was determined by microscopic examination that the number of conidiospores in the suspension significantly exceeds the number of other mycelium cells.

2.3. Decontamination of Container Buckets. The volume decontamination effect was examined on cylindrical polytetrafluoroethylene (PTFE) container buckets of heights of $13 \mathrm{~cm}$ and diameters of $7 \mathrm{~cm}$ and $10 \mathrm{~cm}$ for volumes of 0.51 and 11 , respectively. The inside of containers was lined with contaminated cellophane foils which simplify the microbial manipulation. Prepared suspension of microorganisms was spread homogeneously onto the surface of cellophane foil in 

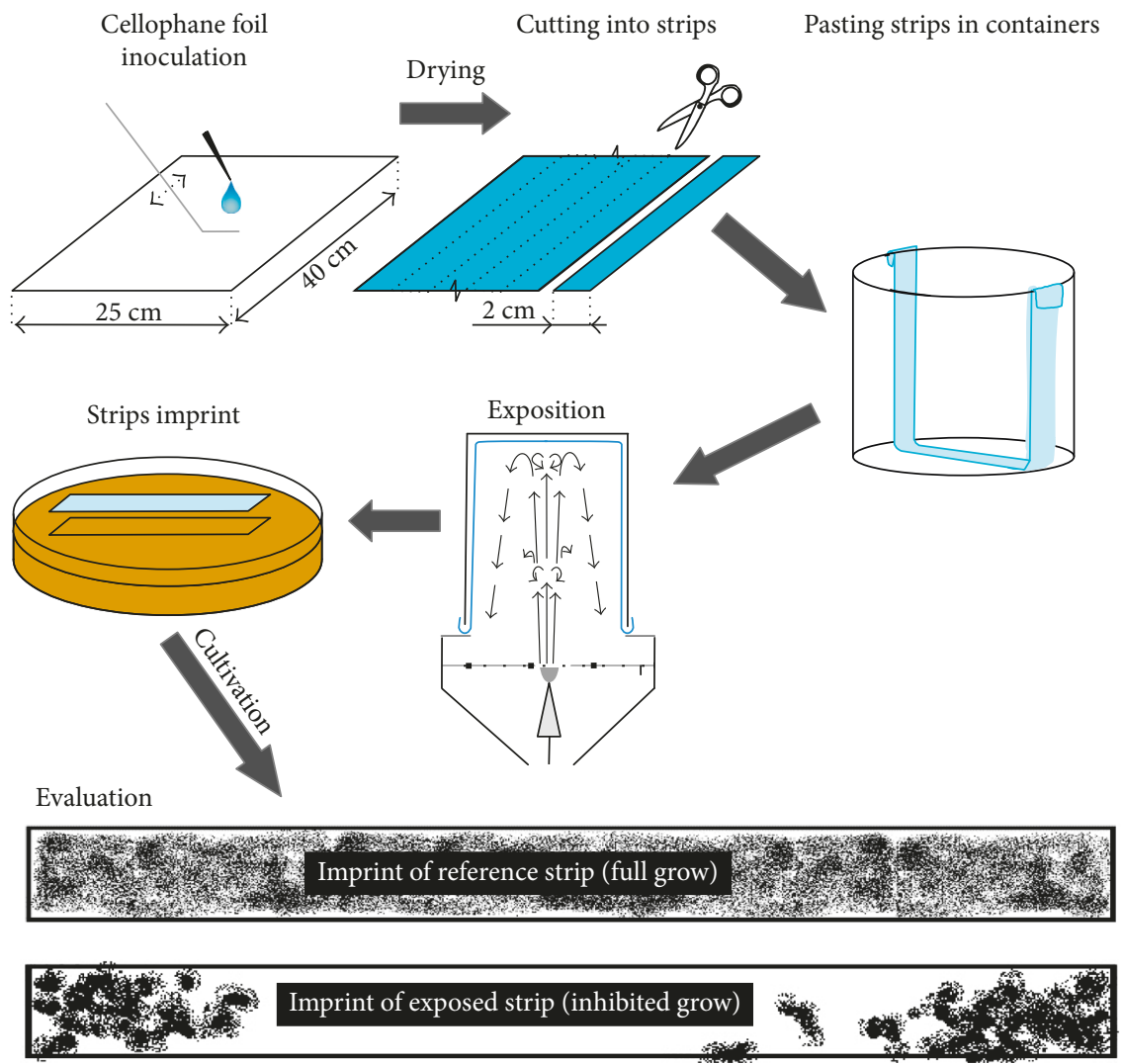

Figure 2: Systematics of the experiment. Cellophane foil is inoculated by the microbial suspension, dried, cut into the strips, and placed on the inner surface of cylindrical containers. Containers are exposed to the NTP with hydrogen peroxide aerosol, strips are imprinted onto the surface of the agar medium and cultivated, and the inhibition zones are determined.

the concentrations of $10^{4} \mathrm{cfu} / \mathrm{cm}^{2}$ and $10^{3} \mathrm{cfu} / \mathrm{cm}^{2}$ for bacteria and micromycetes, respectively. After one hour drying at common room temperature $\left(22^{\circ} \mathrm{C}\right)$ and humidity $(40 \%)$, the foil was cut into strips $(2 \mathrm{~cm} \times 33 \mathrm{~cm}$ for 0.51 cup and $2 \mathrm{~cm} \times 36 \mathrm{~cm}$ for 11 cups) and placed on the inner surface of cylindrical containers and exposed to one of described decontamination methods. To transfer the spores from foils to agar, both the exposed and reference foils were imprinted onto the surface of agar and incubated at $37^{\circ} \mathrm{C}$ for 1 day or at $25^{\circ} \mathrm{C}$ for 5 days in the case of bacteria or micromycetes, respectively. The operating sequence together with the particular sizes of used foils and cylinders is depicted in Figure 2. All experiments were performed in triplicate.

In first set of exposures, our previous study 36 was followed to confirm the inactivation properties of NTP for 3D objects. Moreover, also the spatial distribution of inhibition effect efficiency was determined. The prepared samples of 0.51 containers with limited number or microorganism species S. epidermidis, C. sphaerospermum, and $A$. niger were exposed to NTP with addition of pure water aerosol, to NTP with addition of hydrogen peroxide aerosol, and to the hydrogen peroxide aerosol without the NTP. Samples were exposed for 5, 10, 15, 30, 60, and $120 \mathrm{~s}$. The inhibition effect was denoted as full for no colony growth, as partial for observable isolated colonies (lower than approx. $30 \mathrm{cfu} / \mathrm{cm}^{2}$ ), and the continuous overgrown (higher than approx. $30 \mathrm{cfu} / \mathrm{cm}^{2}$ ) was denoted as no inhibition.
Afterwards, the efficiency of inactivation for a broader spectrum of all mentioned microorganisms was examined in both container types. Prepared samples were exposed for 30 , 60 , and $120 \mathrm{~s}$ to the combination of NTP with hydrogen peroxide aerosol. The inhibition effect was observed both as the inhibition zone without any growth of colony and as the number of grown cfu.

2.4. Decontamination of Commercial Cups. To confirm the decontamination effect of used apparatus for direct practical application, the decontamination was studied on commercial polypropylene (PP) 0.51 cups (Wimex s.r. o., Czech Republic) of height of $13.5 \mathrm{~cm}$ and of bottom and top diameter of $5.5 \mathrm{~cm}$ and $9 \mathrm{~cm}$, respectively. Twenty clean cups were contaminated by artificial or airborne contamination.

For artificial contamination, the inside surface of a cup was sprayed homogeneously by $2 \mathrm{ml}$ of water suspension of A. oryzae or Alternaria sp. in concentration of $10^{3} \mathrm{cfu} / \mathrm{ml}$ with Tween 80 in ratio $0.1 \%$ and dried for one hour at common room temperature $\left(22^{\circ} \mathrm{C}\right)$ and humidity $(40 \%)$. Consequently, cups were exposed for 10, 15, 30, 60, and $120 \mathrm{~s}$ to the combination of NTP with hydrogen peroxide aerosol.

For airborne contamination, cups were kept open in the laboratory for one week and ten of them were exposed to the NTP with hydrogen peroxide aerosol for $30 \mathrm{~s}$. 
TABle 1: Decontamination effect of all used methods in 0.51 cylindrical containers for S. epidermidis, C. sphaerospermum, and A. niger indicated only qualitatively.

\begin{tabular}{|c|c|c|c|c|c|c|c|c|}
\hline \multirow{2}{*}{ Method } & \multirow{2}{*}{ Microorganism } & \multicolumn{7}{|c|}{ Extent of decontamination after exposure time (s) } \\
\hline & & 0 & 5 & 10 & 15 & 30 & 60 & 120 \\
\hline \multirow{3}{*}{ NTP with hydrogen peroxide aerosol } & S. epidermidis & No & Full & Full & Full & Full & Full & Full \\
\hline & A. niger & No & No & Partial & Full & Full & Full & Full \\
\hline & C. sphaerospermum & No & No & Partial & Partial & Full & Full & Full \\
\hline \multirow{3}{*}{ NTP with pure water aerosol } & S. epidermidis & No & No & No & No & No & No & No \\
\hline & A. niger & No & No & No & No & No & No & No \\
\hline & C. sphaerospermum & No & No & No & No & No & No & No \\
\hline \multirow{3}{*}{ Hydrogen peroxide aerosol } & S. epidermidis & No & No & No & No & No & No & No \\
\hline & A. niger & No & No & No & No & No & No & No \\
\hline & C. sphaerospermum & No & No & No & No & No & No & No \\
\hline
\end{tabular}

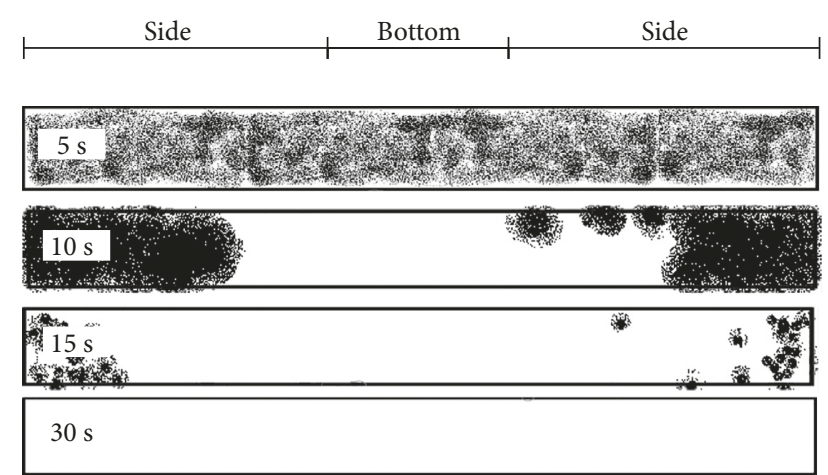

Figure 3: The spatial distribution of inhibition effect for C. sphaerospermum for several exposure times.

After, all cups were filled with prepared potato-carrot broth with the addition of $50 \mathrm{~g}$ of glucose per 11 as model content, closed to prevent contamination, and kept in room temperature for one week. Finally, the number of grown micromycetal colonies on the broth surface was counted. All experiments were performed in triplicate.

\section{Results and Discussion}

Table 1 shows the results for decontamination of samples contaminated by $S$. epidermidis, C. sphaerospermum, and A. niger in 0.51 cylindrical container buckets by all three mentioned methods. Obtained results were identical for all three particular repetitions. Observable decontamination occurred after the exposure to the NTP with hydrogen peroxide aerosol only, where the full decontamination occurred within $5 \mathrm{~s}$ of exposure for $S$. epidermidis (4 $\log 10$ reduction) and within $30 \mathrm{~s}$ of exposure for C. sphaerospermum and A. niger (3 $\log 10$ reduction). For other methods, the decontamination was not observable, so that it cannot be declared neither as inhibition zone nor countable colonies even after $120 \mathrm{~s}$. These results correspond with our previous observation and confirm that the combination of NTP and hydrogen peroxide aerosol is much more efficient than their single action for volume decontamination also.

On this basis, in following experiments, the samples were exposed to the NTP in the aerosol of hydrogen peroxide only. The spatial distribution of inhibition effect for C. sphaerospermum is depicted in Figure 3. The inhibition
TABLE 2: Decontamination effect of NTP with hydrogen peroxide aerosol in 0.51 cylindrical containers indicated as both inhibition zone (\% of area) and total cfu for exposure time $(t)$.

\begin{tabular}{lccc}
\hline \multirow{2}{*}{ Microorganism } & \multicolumn{3}{c}{ Inhibition zone (\% of area)/grown cfu } \\
& $t=30 \mathrm{~s}$ & $t=60 \mathrm{~s}$ & $t=120 \mathrm{~s}$ \\
\hline S. epidermidis & $100 / 0$ & $100 / 0$ & $100 / 0$ \\
A. niger & $100 / 0$ & $100 / 0$ & $100 / 0$ \\
C. sphaerospermum & $100 / 0$ & $100 / 0$ & $100 / 0$ \\
Eurotium sp. strain 1 & $100 / 0$ & $100 / 0$ & $100 / 0$ \\
Eurotium sp. strain 2 & $100 / 0$ & $100 / 0$ & $100 / 0$ \\
A. oryzae & $70 \pm 5 / 10 \pm 5$ & $100 / 0$ & $100 / 0$ \\
T. atroviride & $75 \pm 5 / 10 \pm 5$ & $100 / 0$ & $100 / 0$ \\
Alternaria sp. & $60 \pm 5 / 30 \pm 5$ & $80 \pm 5 / 5 \pm 3$ & $100 / 0$ \\
\hline
\end{tabular}

TABLE 3: Decontamination effect of NTP with hydrogen peroxide aerosol in 11 cylindrical containers indicated as both inhibition zone (\% of area) and total cfu for exposure time $(t)$.

\begin{tabular}{lccc}
\hline \multirow{2}{*}{ Microorganism } & \multicolumn{3}{c}{ Inhibition zone (\% of area)/grown cfu } \\
& $t=30 \mathrm{~s}$ & $t=60 \mathrm{~s}$ & $t=120 \mathrm{~s}$ \\
\hline S. epidermidis & $100 / 0$ & $100 / 0$ & $100 / 0$ \\
A. niger & $100 / 0$ & $100 / 0$ & $100 / 0$ \\
C. sphaerospermum & $100 / 0$ & $100 / 0$ & $100 / 0$ \\
Eurotium sp. & $40 \pm 5 / 30 \pm 5$ & $100 / 0$ & $100 / 0$ \\
strain 1 & & & \\
Eurotium sp. & $35 \pm 5 / 100 \pm 10$ & $100 / 0$ & $100 / 0$ \\
strain 2 & $30 \pm 5 / 10 \pm 5$ & $70 \pm 5 / 5 \pm 3$ & $100 / 0$ \\
A. oryzae & $20 \pm 5 / 10 \pm 5$ & $80 \pm 5 / 5 \pm 3$ & $100 / 0$ \\
T. atroviride & $35 \pm 5 /$ uncount & $75 \pm 5 / 20 \pm 5$ & $80 \pm 5 / 5 \pm 3$ \\
Alternaria sp. & & \multicolumn{3}{c}{}
\end{tabular}

zone becomes to be visible after $10 \mathrm{~s}$ exposure in the center which corresponds to the bottom of buckets, and for longer exposure times, it enlarges and takes the whole area. The gradual extending of inhibition zone from the center corresponds with the airflow induced by the discharge ion wind, which is a characteristic of point-to-point/wire/plane discharges. For more details about the plasma sources and their properties, see, for example, our previous works [40, 41] dealing with point-to-point cometary discharge, demonstrative work about the ion source induced airflow [42], or the review of several common plasma sources [43] suitable for decontamination. 
TABle 4: Decontamination effect of all used methods in 0.51 cylindrical containers for A. oryzae and Alternaria sp.

\begin{tabular}{lcccccc}
\hline \multirow{2}{*}{ Microorganism } & \multicolumn{4}{c}{ Grown cfu } \\
& $t=0 \mathrm{~s}$ & $t=10 \mathrm{~s}$ & $t=15 \mathrm{~s}$ & $t=30 \mathrm{~s}$ & $t=60 \mathrm{~s}$ & $t=120 \mathrm{~s}$ \\
\hline A. oryzae & Uncount & 5 & 0 & 0 & 0 \\
Alternaria sp. & Uncount & Uncount & $500 \pm 100$ & $50 \pm 10$ & $4 \pm 3$ & 0 \\
\hline
\end{tabular}

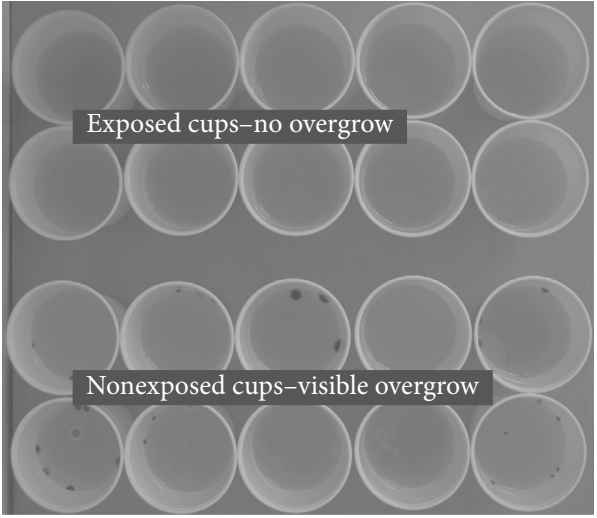

FIGURE 4: The picture of exposed (upper ten) and nonexposed (bottom ten) airborne-contaminated cups after cultivation.

The results of decontamination of all species for both sizes of containers are presented in Tables 2 and 3. In 0.51 containers, the full decontamination occurs for most of species after shortest exposure of $30 \mathrm{~s}$ and the full decontamination for all species occurs after exposure of $120 \mathrm{~s}$. In 11 containers, the decontamination after $30 \mathrm{~s}$ was only partial for most of species and the total decontamination occurred after $120 \mathrm{~s}$ of exposure for all species except Alternaria sp. The results show that the bacterium S. epidermidis is more sensitive than all micromycetes species and that from selected micromycetal species, Alternaria sp. is the most resistant one. As expected, the longer exposure times are necessary for larger volume buckets.

The results for decontamination of artificially contaminated commercial PP cups are given in Table 4 . The number of cultivable cfu decreases with the time of exposure. For A. oryzae, representing the sensitive species, the strong inhibition occurs after $10 \mathrm{~s}$ of exposure and the full inhibition occurs for $15 \mathrm{~s}$ and longer exposures. For the most resistant one, Alternaria sp., the inhibition effect is visible after $15 \mathrm{~s}$ of exposure and the full inhibition occurs after $120 \mathrm{~s}$ exposure. For the airborne contamination, it was found that for nonexposed cups, approximately three grown micromycete colonies per one cup are observed (2.5 \pm 2.2$)$; however, in exposed cups, no grown colonies are observed. These results make this synergy effect of hydrogen peroxide and nonthermal plasma potentially applicable to the practice. For example, the jam or ketchup production companies in Czechia have permanent problems with spoilage in plastic-packed products. The picture of cups after cultivation is shown in Figure 4. In this case, the number of cfu does not represent the real number of culturable cfu in cups, but it has to demonstrate the potential of present microorganisms to spoil the content, Q.E.D.
In our previously mentioned work [37], the discharge denominated as pulseless glow almost identical with that one used in this study. The discharge burned under similar geometry and identical electrical and chemical characteristics: in time constant voltage of $2.7 \mathrm{kV}$ and current of $500 \mu \mathrm{A}$ where no pulses were recorded by $150 \mathrm{MHz}$ bandwidth oscilloscope; emission spectrum was identical with pulseless glow one. The dominant nitrogen $\mathrm{N}_{2}$ bands were detected; the lower intensity of $\mathrm{N}_{2}^{+}$indicates the high electron temperature important for microbicidal activity $[44,45]$; also the minute peak attributed to $\mathrm{OH}^{-}$was detected. Fact that the presence of hydrogen peroxide aerosol in the discharge atmosphere did not change its evaluated characteristics indicates that the rapid increase of microbicidal activity must be induced in the postdischarge dark phase. The main mechanisms of hydrogen peroxide activity may be its dissociation (for details, see our previous paper [35]):

$$
\mathrm{e}^{-}+\mathrm{H}_{2} \mathrm{O}_{2} \longrightarrow \mathrm{OH}^{-}+\mathrm{OH}^{-}
$$

Presented apparatus seems to be a potential alternative to several common decontamination methods based on hydrogen peroxide. Addition of the NTP part to current peroxide-based methods would be very easy and cheap and may help to increase the decontamination efficiency, increase the speed of production line, or decrease the amount or concentration of applied peroxide, or solve the contamination problems in production lines where it is difficult to ensure fully aseptic conditions. The decrease of concentration of hydrogen peroxide or amount of energy is also important from an ecological point of view.

\section{Conclusions}

Experimental study of the volume decontamination effects of nonthermal plasma generated in corona discharge in combination with hydrogen peroxide aerosol shows much higher efficiency than the single action of NTP or hydrogen peroxide. While the decontamination of single nonthermal plasma or hydrogen peroxide is not observable after $120 \mathrm{~s}$, the strong decontamination effect of their combination occurs after $30 \mathrm{~s}$ of exposure. This phenomenon was demonstrated on one bacterial and seven micromycete species in both container buckets and 0.51 commercial cups. Along with the total inactivation of airborne contamination of commercial cups, it predetermines this method as a suitable alternative to the currently used methods based on hydrogen peroxide applications. It may help to reduce the required amount or concentration of hydrogen peroxide, which is also important from an ecological point of view. 


\section{Data Availability}

In Tables 1-4, only the mean values and standard deviations are presented. The reader can access the particular results on request to the corresponding author.

\section{Conflicts of Interest}

The authors declare that they have no conflicts of interest.

\section{Acknowledgments}

This work was financially supported by the specific university research (MSMT no. 21-SVV/2018) and by the MSMT CR (Grant no. LTC17083) in frame of the COST CA15107 MultiComp.

\section{References}

[1] C. Morris, A. L. Brody, and L. Wicker, "Non-thermal food processing/preservation technologies: a review with packaging implications," Packaging Technology and Science, vol. 20, no. 4, pp. 275-286, 2007.

[2] I. A. Ansari and A. K. Datta, "An overview of sterilization methods for packaging materials used in aseptic packaging systems," Food and Bioproducts Processing, vol. 81, no. 1, pp. 57-65, 2003.

[3] L. F. Abreu and J. A. Faria, "Evaluation of a system for chemical sterilization of packages," Packaging Technology and Science, vol. 17, no. 1, pp. 37-42, 2004.

[4] K. K. Kuorwel, M. J. Cran, K. Sonneveld, J. Miltz, and S. W. Bigger, "Evaluation of antifungal activity of antimicrobial agents on cheddar cheese," Packaging Technology and Science, vol. 27, no. 1, pp. 49-58, 2014.

[5] J. F. B. de São José, N. J. de Andrade, A. M. Ramos, M. C. Dantas Vanetti, P. C. Stringheta, and J. B. Paes Chaves, "Decontamination by ultrasound application in fresh fruits and vegetables," Food Control, vol. 45, pp. 36-50, 2014.

[6] M. L. Artíguez and I. M. de Marañón, "Improved process for decontamination of whey by a continuous flow-through pulsed light system," Food Control, vol. 47, pp. 599-605, 2015.

[7] B.-Y. Chen, H.-M. Lung, B. B. Yang, and C.-Y. Wang, "Pulsed light sterilization of packaging materials," Food Packaging and Shelf Life, vol. 5, pp. 1-9, 2015.

[8] Q. Liu, M. Zhang, B. Xu, Z. Fang, and D. Zheng, "Effect of radio frequency heating on the sterilization and product quality of vacuum packaged caixin," Food and Bioproducts Processing, vol. 95, pp. 47-54, 2015.

[9] V. Novickij, A. Grainys, J. Švedienè, A. Paškevičius, and J. Novickij, "Controlled inactivation of Trichophyton rubrum using shaped electrical pulse bursts: parametric analysis," Biotechnology progress, vol. 32, no. 4, pp. 1056-1060, 2016.

[10] M. Laroussi, "Low temperature plasma-based sterilization: overview and state-of-the-art," Plasma Processes and Polymers, vol. 2, no. 5, pp. 391-400, 2005.

[11] V. Scholtz, J. Pazlarová, H. Soušková, J. Khun, and J. Julák, "Nonthermal plasma-a tool for decontamination and disinfection," Biotechnology advances, vol. 33, no. 6, pp. 1108-1119, 2015.

[12] R. Ma, G. Wang, Y. Tian, K. Wang, J. Zhang, and J. Fang, "Non-thermal plasma-activated water inactivation of foodborne pathogen on fresh produce," Journal of hazardous materials, vol. 300, pp. 643-651, 2015.
[13] Y. Xu, Y. Tian, R. Ma, Q. Liu, and J. Zhang, "Effect of plasma activated water on the postharvest quality of button mushrooms, agaricus bisporus," Food chemistry, vol. 197, pp. 436-444, 2016.

[14] V. Scholtz, J. Julák, and V. Kříha, “The microbicidal effect of low-temperature plasma generated by corona discharge: comparison of various microorganisms on an agar surface or in aqueous suspension," Plasma Processes and Polymers, vol. 7, no. 3-4, pp. 237-243, 2010.

[15] H. Soušková, V. Scholtz, J. Julák, L. Kommová, D. Savická, and J. Pazlarová, "The survival of micromycetes and yeasts under the low-temperature plasma generated in electrical discharge," Folia Microbiologica, vol. 56, no. 1, pp. 77-79, 2011.

[16] D. B. Graves, "The emerging role of reactive oxygen and nitrogen species in redox biology and some implications for plasma applications to medicine and biology," Journal of Physics D: Applied Physics, vol. 45, no. 26, article 263001, 2012.

[17] V. Scholtz, J. Julák, V. Kř́ha, J. Mosinger, and S. Kopecká, "Decontamination effects of low-temperature plasma generated by corona discharge. Part II: new insights," Prague Medical Report, vol. 108, no. 2, pp. 128-146, 2007.

[18] K. Oehmigen, J. Winter, M. Hähnel et al., "Estimation of possible mechanisms of Escherichia coli inactivation by plasma treated sodium chloride solution," Plasma Processes and Polymers, vol. 8, no. 10, pp. 904-913, 2011.

[19] C. Nerín, M. Aznar, and D. Carrizo, "Food contamination during food process," Trends in Food Science and Technology, vol. 48, pp. 63-68, 2016.

[20] I. Ozturk, O. Sagdic, H. Yalcin, T. D. Capar, and M. H. Asyali, "The effects of packaging type on the quality characteristics of fresh raw pistachios (Pistacia vera 1.) during the storage," LWT-Food Science and Technology, vol. 65, pp. 457-463, 2016.

[21] I. A. Soloshenko, V. V. Tsiolko, V. A. Khomich et al., "Features of sterilization using low-pressure dc-discharge hydrogenperoxide plasma," IEEE Transactions on Plasma Science, vol. 30, no. 4, pp. 1440-1444, 2002.

[22] J. Schneider, K. M. Baumgärtner, J. Feichtinger et al., "Investigation of the practicability of low-pressure microwave plasmas in the sterilisation of food packaging materials at industrial level," Surface and Coatings Technology, vol. 200, no. 1, pp. 962-966, 2005.

[23] M. Deilmann, H. Halfmann, N. Bibinov, J. Wunderlich, and P. Awakowicz, "Low-pressure microwave plasma sterilization of polyethylene terephthalate bottles," Journal of Food Protection, vol. 71, no. 10, pp. 2119-2123, 2008.

[24] T. Lee, P. Puligundla, and C. Mok, "Inactivation of foodborne pathogens on the surfaces of different packaging materials using low-pressure air plasma," Food Control, vol. 51, pp. 149-155, 2015.

[25] Y. Sen and M. Mutlu, "Sterilization of food contacting surfaces via non-thermal plasma treatment: a model study with Escherichia coli-contaminated stainless steel and polyethylene surfaces," Food and Bioprocess Technology, vol. 6, no. 12, pp. 3295-3304, 2013.

[26] M. Heise, W. Neff, O. Franken, P. Muranyi, and J. Wunderlich, "Sterilization of polymer foils with dielectric barrier discharges at atmospheric pressure," Plasmas and polymers, vol. 9, no. 1, pp. 23-33, 2004.

[27] H. Yun, B. Kim, S. Jung et al., "Inactivation of listeria monocytogenes inoculated on disposable plastic tray, aluminum foil, and paper cup by atmospheric pressure plasma," Food Control, vol. 21, no. 8, pp. 1182-1186, 2010.

[28] P. Muranyi, J. Wunderlich, and H.-C. Langowski, "Modification of bacterial structures by a low-temperature gas plasma 
and influence on packaging material," Journal of Applied Microbiology, vol. 109, no. 6, pp. 1875-1885, 2010.

[29] J.-W. Kim, P. Puligundla, and C. Mok, "Microbial decontamination of dried laver using corona discharge plasma jet (cdpj)," Journal of Food Engineering, vol. 161, pp. 24-32, 2015.

[30] L. Ragni, A. Berardinelli, L. Vannini et al., "Non-thermal atmospheric gas plasma device for surface decontamination of shell eggs," Journal of Food Engineering, vol. 100, no. 1, pp. 125-132, 2010.

[31] N. N. Misra, S. Patil, T. Moiseev et al., "In-package atmospheric pressure cold plasma treatment of strawberries," Journal of Food Engineering, vol. 125, pp. 131-138, 2014.

[32] S. K. Pankaj, C. Bueno-Ferrer, N. N. Misra et al., "Applications of cold plasma technology in food packaging," Trends in Food Science and Technology, vol. 35, no. 1, pp. 5-17, 2014.

[33] K. T. Lee, J. M. Goddard, and J. H. Hotchkiss, "Plasma modification of polyolefin surfaces," Packaging Technology and Science, vol. 22, no. 3, pp. 139-150, 2009.

[34] P. M. Schneider, "New technologies and trends in sterilization and disinfection," American Journal of Infection Control, vol. 41, no. 5, pp. S81-S86, 2013.

[35] M. Čeřovskỳ, J. Khun, K. Rusová, V. Scholtz, and H. Soušková, "Inactivation of possible micromycete food contaminants using the low-temperature plasma and hydrogen peroxide," Plasma Physics Reports, vol. 39, no. 9, pp. 763-767, 2013.

[36] V. Scholtz, J. Khun, H. Soušková, and M. Čeřovskỳ, "Inactivation of possible microorganism food contaminants on packaging foils using the non-thermal plasma and hydrogen peroxide," Plasma Physics Reports, vol. 41, no. 7, pp. 586-590, 2015.

[37] J. Khun, V. Scholtz, P. Hozák, P. Fitl, and J. Julák, "Various DC driven point-to-plain discharges as non-thermal plasma sources and their bactericidal effects," Plasma Sources Science and Technology, vol. 27, no. 6, article 065002, 2018.

[38] Y. S. Akishev, M. E. Grushin, I. V. Kochetov, A. P. Napartovich, M. V. Pan'kin, and N. I. Trushkin, "Transition of a multipin negative corona in atmospheric air to a glow discharge," Plasma Physics Reports, vol. 26, no. 2, pp. 157-163, 2000.

[39] Y. S. Akishev, M. E. Grushin, V. B. Karal'Nik et al., "Evolution of the radial structure of a negative corona during its transformation into a glow discharge and a spark," Plasma Physics Reports, vol. 29, no. 2, pp. 176-186, 2003.

[40] V. Scholtz and J. Julak, "Plasma jetlike point-to-point electrical discharge in air and its bactericidal properties," IEEE Transactions on Plasma Science, vol. 38, no. 8, pp. 1978-1980, 2010.

[41] V. Scholtz, E. Kvasničková, and J. Julák, "Microbial inactivation by electric discharge with metallic grid," Acta Physica Polonica A, vol. 124, no. 1, pp. 62-68, 2013.

[42] E. Karakas, A. Begum, and M. Laroussi, "A positive coronabased ion wind generator," IEEE Transactions on Plasma Science, vol. 36, no. 4, pp. 950-951, 2008.

[43] J. Ehlbeck, U. Schnabel, M. Polak et al., "Low temperature atmospheric pressure plasma sources for microbial decontamination," Journal of Physics D: Applied Physics, vol. 44, no. 1, article $013002,2010$.

[44] Z. Lianzhu, Z. Shuxia, and M. Xiulan, "Characterization of nitrogen glow discharge plasma via optical emission spectrum simulation," Plasma Science and Technology, vol. 10, no. 4, pp. 455-462, 2008.

[45] Z. Machala, M. Janda, K. Hensel et al., "Emission spectroscopy of atmospheric pressure plasmas for bio-medical and environmental applications," Journal of Molecular Spectroscopy, vol. 243, no. 2, pp. 194-201, 2007. 


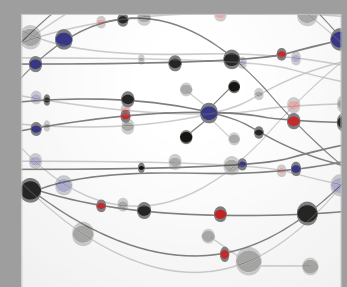

The Scientific World Journal
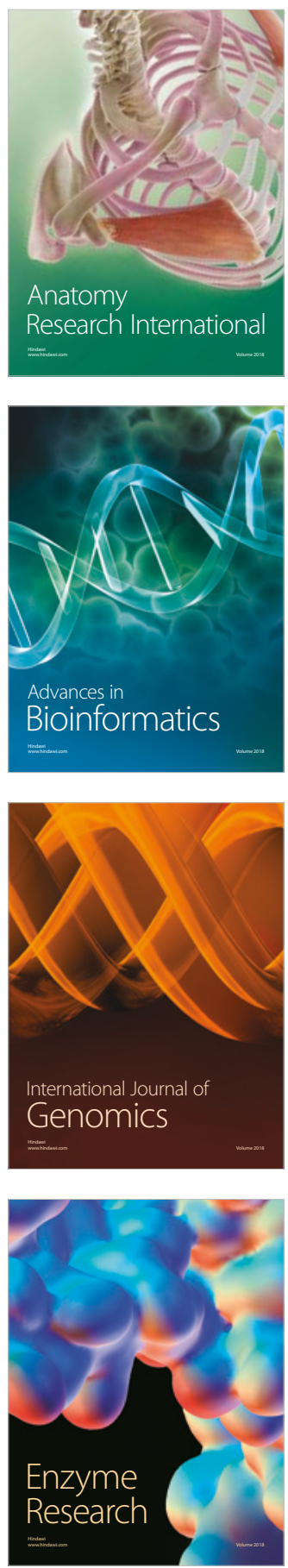
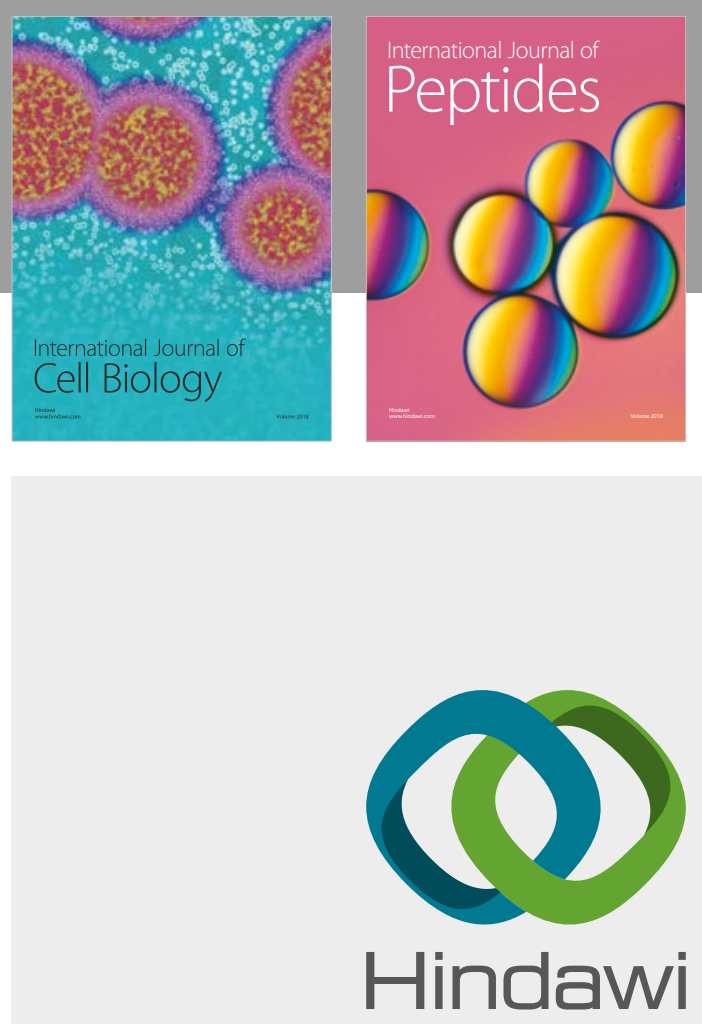

Submit your manuscripts at

www.hindawi.com
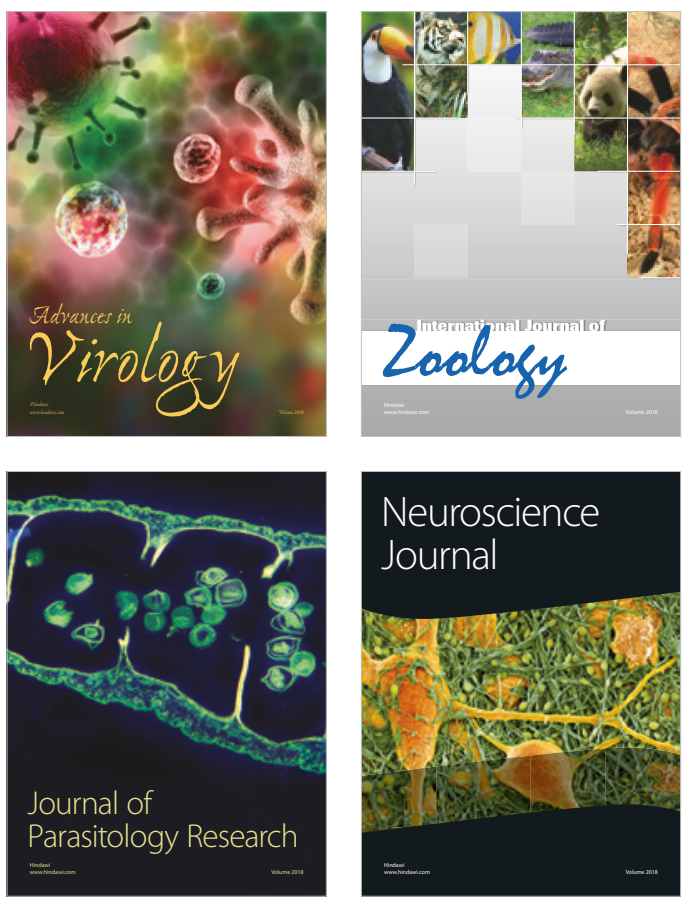
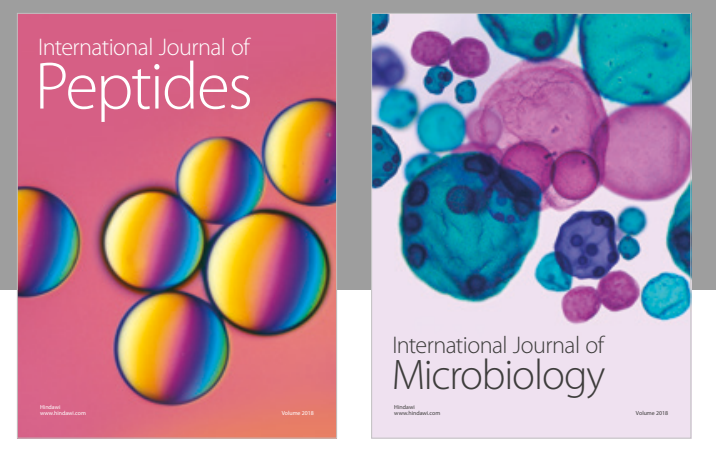

nternational Journal of Microbiology
Journal of
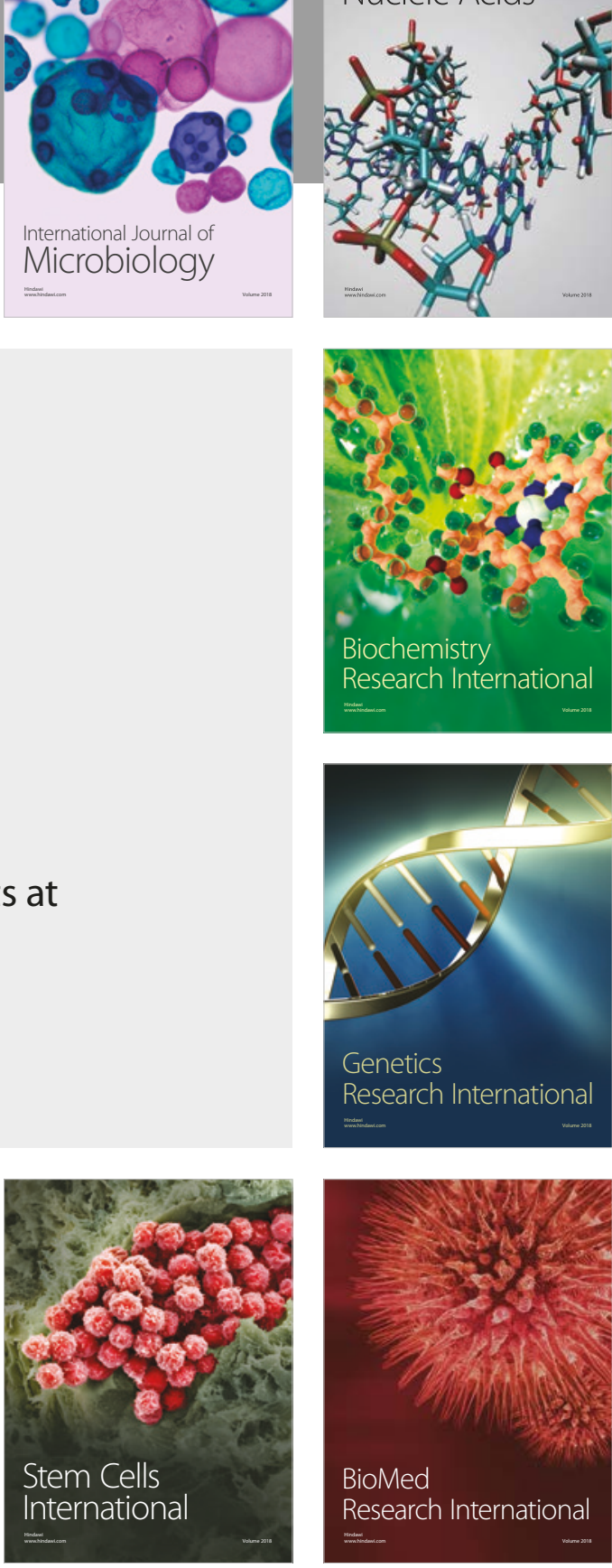
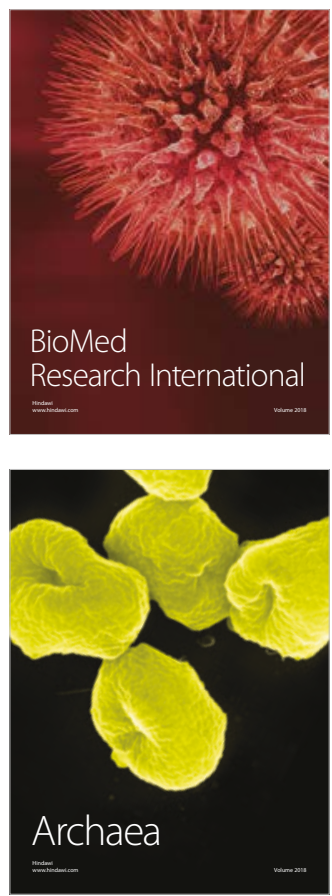